\title{
USING UNDERGRADUATES TO PREPARE INTERNATIONAL TEACHING ASSISTANTS FOR THE AMERICAN CLASSROOM
}

\author{
Warren E. Christian, Brian J. Rybarczyk \\ University of North Carolina at Chapel Hill
}

This chapter describes how undergraduates may be used in the training of international teaching assistants (ITAs) in three ways: as conversation partners, classroom consultants, and guest instructors. Increasing the contact between undergraduates and international graduate students before they meet in the classroom as students and instructors can benefit each group. After a brief review of the literature that explores the challenges ITAs face in the American university classroom, we describe the roles that undergraduates may perform in training ITAs, explain the benefits to both ITAs and undergraduates, and provide a list of best practices for including undergraduates in ITA training.

0

American universities continue to enroll a significant number of international graduate students. From 1980 to 1990, the number of doctoral degrees in the United States awarded to international students increased from 13 percent to 25 percent and has remained relatively stable since 1990 (National Center for Educational Statistics, 2012b). 
While American universities continue to attract graduate students from around the world, the incorporation of international graduate students into American universities has not been seamless. One area where the discord is most evident is the relationship between American undergraduate students and international teaching assistants (ITAs).

Like many other graduate students, international graduate students are often called on to provide instruction to American undergraduates as teaching assistants, especially for larger, introductory courses where undergraduate students are less likely to have prior knowledge of basic discipline-specific concepts. Undergraduates commonly report that they cannot understand and cannot learn from their ITAs (Alberts, 2008; Bailey, 1983; Plakans, 1997; Williams, 2011). Those complaints of undergraduates have been heard outside the academy. In the 1980s and 1990 s, more than fifteen states passed legislation mandating the English fluency of instructors in higher education in an effort to ensure that instruction is delivered in understandable English (Brown, Fishman, \& Jones, 1990; King, 1998). Many universities have responded by designing programs to help ITAs acclimate to the expectations of the American university classroom and learn ways of communicating with American undergraduates. The training of ITAs has been a topic of academic research for over thirty years (Damarin \& West, 1979; Kaplan, 1989; Kaufman \& Brownworth, 2006; Kim \& Kubota, 2012; Sarkisian, 1986; Smith \& Ainsworth, 1987).

This chapter first gives a brief review of the literature that focuses on the sources and potential solutions to the challenges faced by ITAs in the American university classroom. Second, it discusses how the University of North Carolina (UNC) at Chapel Hill's Preparing International Teaching Assistants Program (PITAP) incorporates undergraduate volunteers into ITA preparation. Third, it identifies the benefits of the PITAP approach for both the international graduate students and undergraduate volunteers. A best practices section at the end shares advice on how to incorporate undergraduates incorporated into ITA training.

\section{ITA Literature}

The ITA literature identifies three main actors in the communication difficulties between undergraduates and ITAs: ITAs, universities, and undergraduates. Most of this literature focuses on the role of ITAs. For example, ITAs sometimes do not have the English language proficiency skills, pedagogical skills, and cultural understanding necessary to be effective teachers in American classrooms. Some scholars explore the role 
that universities play in the sometimes strained relationships between ITAs and their undergraduate students. Other authors examine how undergraduate students' perspectives may contribute to the issues ITAs face.

Undergraduates, universities, and ITAs, however, are not monolithic groups. While most undergraduates in the United States are U.S. citizens and their first language is English, increasing numbers of undergraduates in the United States come from other countries and have a first language other than English.

ITAs come from all over the world and speak a variety of languages in their home countries, including English. In 2011, 63.9 percent of foreign students enrolled in American universities were from Asia (National Center for Educational Statistics, 2012c). The countries most represented were China ( 21.8 percent) and India (14.4 percent). In addition, foreign graduate students are not dispersed equally throughout all academic departments (National Center for Educational Statistics, 2012a). The fields with the highest percentages of doctoral degrees awarded to foreign students in 2011 were engineering (56 percent), computer and information sciences ( 50 percent), mathematics and statistics (47 percent), agriculture ( 41 percent), and physical sciences ( 41 percent).

\section{The Role of ITAs}

There are many possible sources for undergraduates' complaints about ITAs. ITAs' English language skills are the most commonly given reason for communication breakdowns in the classroom. ITAs may not possess an extensive enough vocabulary in English needed to provide clear explanations (Alberts, 2008), and their nonstandard pronunciation patterns have been shown to promote miscommunication with undergraduate students (Anderson-Hsieh, 1990; Molholt, 1988; Morley, 1991). They sometimes place emphasis in the wrong areas-if they place emphasis at all (Hahn, 2004). Placing stress on certain words often marks new or contrasting information and aids listeners in understanding. ITAs may not make the correct tone choice needed to display empathy and involvement to American audiences. In addition, tone choice can change the connotative meaning of sentences (Pickering, 2001, 2004). ITAs may not make effective use of discourse markers that can be used to signal how ideas are related, draw attention to main points, transition between topics, and in general make speech more comprehensible (Tyler, 1992; Williams, 1992). While the literature points to ITAs' English language skills as the greatest potential source for miscommunication, it is not the only source. 
ITAs' teaching skills and styles may not be appropriate for American undergraduate students. ITAs may not explain the connections between different pieces of course content and may fail to provide the necessary context, which impedes students' learning (Byrd \& Constantinides, 1992). They do not always sufficiently elaborate their main points or direct students' attention to the most salient aspects of a lesson (Rounds, 1987; Williams, 1992). ITAs often do not express appropriate nonverbal actions to connect with students (Byrd \& Constantinides, 1992; Jenkins \& Parra, 2003). For instance, in the United States, making eye contact, smiling, and leaning forward may help signal involvement and listening.

The ITA literature indicates that many of the difficulties undergraduates encounter may be due to ITAs' different styles of teaching and English language use, but there is still at least one other possible source for miscommunication: cultural differences, which may also contribute to the strained relationships between ITAs and undergraduates. ITAs may come from an educational system where students are expected to be silent during class and not question their professors, and they may not deal well with American students who expect to participate actively and ask questions in the classroom (Sarkisian, 2006). ITAs and students may have different definitions about what constitutes appropriate classroom behavior and the roles that TAs or instructors in American university culture are expected to fill (Alberts, 2008; Ard, 1989; LeGros \& Faez, 2012). ITAs are often unfamiliar with the secondary education experiences of American undergraduate students and thus have difficulty connecting new information with students' prior knowledge (Williams, 2011). Shiao-Yun Chiang and Han-Fu Mi (2008) point out that while ITAs' language may be understood, the meaning may still be lost due "partly to interactional procedures and partly to professional experiences that are both embedded deeply in one's sociocultural background" (p. 279). According to the literature related to ITAs' instruction of undergraduates, ITAs' language, teaching, and intercultural skills can cause perceived challenges for undergraduates. However, all of the onus for the relations between ITAs and undergraduates should not be placed on ITAs.

\section{The University's Role}

While most of the literature describes how ITAs are responsible for the miscommunication in the classroom, some research emphasizes the university's role. Robert Kaplan (1989) argues that universities share some of the blame by thrusting international graduate students into teaching 
assistantships soon after they arrive in the country without adequate preparation. Michele Fisher (1985) urges universities to conduct selfstudies in order to gauge how many international students they can adequately support. Others fault universities for not adequately testing international graduate students' English language skills prior to offering them admission or before assigning them instructional roles. These authors promote better language testing methods as an important response to the difficulties ITAs may face in American university classrooms (Halleck \& Moder, 1995; Hoekje \& Linnell, 1994; Xi, 2007; Yule \& Hoffman, 1990).

Universities and ITAs each play a significant role in the sometimes tense interactions between undergraduates and ITAs, but the role of undergraduates should also be considered.

\section{The Undergraduates' Role}

Commendably, some authors place a portion of the communicative burden on American undergraduates. Donald Rubin (1992) has conducted studies where American undergraduates are asked to evaluate a prerecorded lesson delivered by a native English speaker in standard American English. An image of a Caucasian woman meant to represent the instructor was shown to half of the students, and an image of an Asian woman was shown to the other half. Although all students heard the same recording, students shown the Asian woman performed worse in a test of listening comprehension and detected a nonexistent accent. Rubin concludes that no matter how well Asian ITAs are able to improve their spoken English and approximate American speech patterns, American undergraduates may still find fault with their teaching due to their Asianness.

When Fred Fitch and Susan Morgan (2003) examined undergraduates' stories about ITAs, they found a common narrative structure that viewed the ITA negatively, the undergraduate student as victim, and the university as the villain. They postulate that stories that portray ITAs negatively circulate throughout universities and account for much of undergraduates' apprehension toward ITAs. Donald Rubin and Kim Smith (1990) found that 40 percent of undergraduates actively avoided course sections taught by ITAs, and undergraduates who had more experience with ITAs were more likely to rate them favorably. According to some of the literature, undergraduates should share part of the blame for the challenges faced by ITAs in the American university classroom.

Realizing that undergraduates play a role in the strained classroom relationships between ITAs and undergraduates, Rubin (1992) advocates 
for programs that facilitate enjoyable gatherings between ITAs and American undergraduates. However, he laments, "such programs will require labor-intensive and time-intensive efforts, and will not be practical for the sort of large-scale sensitization needed on college campuses" (p. 528).

\section{The Solution}

The most practical and widely used solution is training ITAs in the skills they need to develop to become effective instructors. These programs usually focus on a combination of English language skills, teaching skills, and intercultural communication. This generally occurs in one of four ways: orientations that take place a few days before the academic year begins; presession programs that last one to four weeks, usually before the semester begins; concurrent-term programs where ITAs enroll in a semester-long course as they engage in the roles of a TA; and preterm programs that last a full semester before students begin their TA responsibilities (Constantinides, 1989).

\section{Preparing International Teaching Assistants Program}

PITAP was initiated in 2003 at UNC Chapel Hill, a large, researchintensive university, as a program to support the training of ITAs. The program consists of two semester-long courses: Communicating in the American University Classroom and Advanced Communicating in the American University Classroom. In line with the literature, the courses focus on improving international graduate students' English language skills, teaching skills, and intercultural communication skills. At UNC, the teaching and learning support unit for campus, the Center for Faculty Excellence, does not offer courses or programs targeted specifically to international graduate students. For this reason, PITAP courses are administered through the Graduate School. Each two-credit course is graded on a pass/fail basis. International graduate students enroll voluntarily in the courses, though sometimes at the behest of an advisor. The courses are designed for those who are currently providing instruction as a TA or who are likely to provide instruction as a TA in the future. PITAP currently serves approximately 15 international graduate students each semester. Since 2003, PITAP has served over 250 students.

Undergraduate student volunteers are recruited at the beginning of each academic year. The program seeks volunteers to serve in three ways: as conversation partners, classroom consultants, or guest instructors. 
An advertisement is placed in the campus newspaper and e-mails are sent to listservs informing students of service-oriented opportunities. We have also had great success partnering with undergraduate courses that have a formal service-learning component and have a focus on teaching or international or cultural studies. These service-learning courses require thirty hours of volunteer service per semester that must relate to the topic of the course. The teaching and international aspects of PITAP have fit well with undergraduate service-learning courses in the fields of education and global studies. Some undergraduate volunteers accumulate hours to fulfill their commitment as university-recognized public service scholars.

We invite our volunteers to engage in as many service hours as they would like and invite student volunteers back each semester to continue accumulating service hours. Tapping into this resource of committed service-oriented undergraduate students has been effective, since the program continuously recruits undergraduate volunteers to support the needs of the program and since it is a mutually beneficial arrangement for both the undergraduates and PITAP. Each year, about ten undergraduates volunteer in varying ways.

Programs at other universities have used undergraduate volunteers as evaluators to help decide whether international graduate students are up to the task of being TAs, as guides in ITA workshops, and as commenters during ITA training (Civikly \& Muchisky, 1991; Rubin, 1992; Schneider \& Stevens, 1991).

\section{Conversation Partners}

As part of the program's courses, international graduate students are required to keep a conversation log that provides space to reflect on their language development and progress over the course of the semester. Students must accumulate eight hours of conversations with at least three hours of conversation with American undergraduate students. On our course management website, we post e-mail addresses and short biographical paragraphs for each undergraduate volunteer. International graduate students contact undergraduate volunteers directly to set up a time and place to talk. Most meetings last between thirty minutes and one hour and take place on or near campus. When students or undergraduate volunteers ask what they should talk about during their conversations, we propose that they may be interested in discussing each other's cultures, similar nonacademic interests, and campus life, for example. We also advise students and volunteers to keep conversations informal. We remind students that undergraduate volunteers are experts 
in undergraduate culture and can provide insights into the lives of American undergraduate students in a way that instructors may not be able to provide.

The purpose of the conversation partmers is two-fold. It gives ITAs a chance to practice their informal conversational skills and allows them to get to know undergraduate students. International graduate students are often much more comfortable when speaking in English about their field of study. They are already familiar with the field and often can predict where a conversation is headed. In informal conversation, however, the topic will likely not be in their field of expertise. Also, the topic of discussion can change at a moment's notice, and the course the conversation will take can be very difficult to predict. Our students often say that informal conversations are more difficult than their more formal discussions with peers and colleagues in their same field.

The required conversation partner interactions allow international graduate students to practice these more challenging, informal conversations. In addition, informal conversations allow international graduate students to practice their listening and speaking skills in a realistic setting. We encourage these students to seek feedback from their conversation partners about their English language skills. We also ask them to reflect on what aspects of their English language skills are improving and identify areas where they have room for growth.

Getting to know undergraduate students outside the classroom setting can be beneficial to ITAs as well. One important part of effective teaching is developing rapport with students. Although all graduate students are usually somewhat disconnected from undergraduates, international graduate students are often even more disconnected because of cultural differences, engagement in courses only with other graduate students, and a focus on their scholarship and research productivity. For American TAs, this separation from undergraduates is usually not a problem because they can draw on their own experiences as former undergraduates to help them relate to the undergraduate students they are teaching. International students do not have the same luxury. It will be more difficult for ITAs to develop rapport with American undergraduate students if their only contact with undergraduates comes while they are teaching. By meeting with undergraduate students in a relaxed atmosphere, ITAs can learn about ways to connect with undergraduates. The conversations also provide ITAs with insight into American undergraduate culture, what American undergraduates' value, and what their goals are. ITAs may then use this knowledge to help develop rapport with undergraduate students in their courses. Undergraduates may be able to give ITAs practical advice 
about different campus and local events, ways to get around town, and where to find different goods and services. When ITAs have already had some informal contact with American undergraduate students, a class full of American undergraduates will seem less foreign and less daunting.

Undergraduates who participate as conversation partners also benefit from the experience. They get firsthand experience interacting with students from different cultures. Many of our volunteers have academic interests related to international relations. Talking with international graduate students can help undergraduates contextualize some course content. Sometimes undergraduate volunteers have sought advice about class projects or writing assignments from international graduate students. In several instances, these volunteers have used the opportunity to learn more about a country that they have visited or may visit in the future. Some conversation partners have had a conversation in English and then had a conversation in the first language of the international graduate students when it is also a target language of the undergraduate volunteer. And questions from international students may provide undergraduate students with an opportunity to think critically about elements of American and university cultures.

\section{Classroom Consultants}

Undergraduate volunteers may also be involved in PITAP as classroom consultants. International graduate students enrolled in PITAP courses perform a series of ten-minute microteachings where they teach material from their discipline to the class. During class days when these demonstrations are scheduled, we invite the undergraduate volunteers to join the class to provide feedback. During each microteaching, everyone present in the class (instructors, peers, and undergraduate volunteers) completes a rubric that asks for an evaluation of presentation skills, teaching skills, and task-specific skills. Undergraduate volunteers are instructed to act as if they are in a regular undergraduate class asking questions when they do not understand or need clarification. After each microteaching demonstration, undergraduates, along with international graduate students in the audience, are called on to deliver feedback and suggestions for teaching improvement.

Having undergraduates present during microteachings is beneficial to the international graduate students. Our students observe how undergraduates behave in a classroom setting, gain insight into undergraduates' learning needs and progress, and learn effective and ineffective teaching strategies from an undergraduate perspective. If at the end of an observed 
lesson, undergraduate volunteers report that they learned something new and achieved the desired learning goals of the lesson, then international graduate students know that they have been effective. This small success can help reduce the anxiety that they feel when confronting a classroom full of American undergraduates for the first time.

When giving feedback to international graduate students, undergraduate volunteers frequently validate what we have previously discussed in class. For example, we often urge our graduate students in mathematics and statistics to begin a lesson with an example or use real numbers rather than a complex formula with unfamiliar variables. Undergraduate students have offered similar advice when providing feedback. Hearing the same message from undergraduates is perhaps more salient than hearing it from instructors.

Undergraduates who participate as classroom consultants are asked to think reflectively about their own learning. This opportunity for reflection can help students take ownership of their learning and help them realize what aspects of different teaching styles they find beneficial for their learning. Some classroom consultants have said that the experience has helped them imagine the perspective of instructors and has informed their own presenting and teaching styles.

\section{Undergraduates as Instructors}

On two occasions, we have had undergraduate volunteers develop and deliver lessons to ITAs. The volunteers created a lesson on undergraduate culture and another lesson on idioms and slang common among undergraduates. In both cases, undergraduates gave the graduate students direct insight regarding undergraduates that is inaccessible to us as instructors. For instance, undergraduates taught many contemporary slang terms that we were unaware of but that undergraduate students use frequently in their informal interactions with each other. Undergraduates are often in the best position to provide information about university culture.

A potential area of concern that arises when volunteers serve as conversation partners and classroom consultants is that undergraduates will see themselves in a superior role to international graduate students. Undergraduate volunteers may feel their role is to pass their knowledge on to the international graduate students. They may feel their responsibility is to serve and teach the international graduate students and not also to learn and benefit from their interaction with international graduate students. Yet, paradoxically, having undergraduate volunteers teach 
a lesson can increase the sense that they are learning from international graduate students. During the microteaching demonstrations, undergraduate volunteers who teach a lesson are not only providing feedback; they are also learning from the successes and miscues of international graduate students. As conversation partners, undergraduate volunteers who will go on to provide instruction can use the conversations as an opportunity to gather information that will help structure their planned lesson and make it more relevant and useful to the graduate students. Having the undergraduates teach a lesson helps to place international graduate students and undergraduate volunteers in a similar position where they both can learn from each other. Both can also commiserate about the anxiety that often accompanies teaching. When both international graduate students and undergraduate volunteers offer lessons, they are on a more equal footing.

Undergraduates who serve as guest instructors gain valuable teaching experience. They create learning goals, develop and then implement a lesson plan, and practice managing a classroom. They can gain confidence in their teaching abilities by instructing graduate students in an authentic teaching environment.

\section{Evaluation}

On course evaluations, PITAP students have routinely rated undergraduate students' involvement as one of the most helpful aspects of the course. During the fall 2010 semester, the course incorporated extensive undergraduate involvement in two sections with fifteen international graduate students. Following the course, PITAP students rated feedback from undergraduates associated with microteaching demonstrations above all other aspects, including feedback from instructors, feedback from peers, and reviewing a video of their microteaching demonstration. Two-thirds of the PITAP students rated their interactions with undergraduate conversation partners as "very important and beneficial" or "extremely important and essential to the course." Two-thirds of the PITAP students also rated the session on undergraduate culture taught by undergraduate volunteers as "very important and beneficial" or "extremely important and essential to the course." PITAP students reported that their "confidence as a TA" improved from prior to taking the course to after taking the course. Half of the students rated their confidence as "below average" prior to the course and over two-thirds rated their confidence as "above average" after the course. PITAP students have expressed gratitude for the opportunity to get to know undergraduate students. 


\section{Suggested Best Practices for Incorporating Undergraduates}

We have organized the best practices that we have found in incorporating undergraduates in ITA training into four areas: recruitment and orientation of undergraduate volunteers, conversation partners, classroom consultants, and guest instructors.

\section{Recruitment and Orientation of Undergraduate Volunteers}

o Recruit undergraduate volunteers through student newspapers, community-service-oriented listservs, and undergraduate courses and majors related to education and international relations.

o Encourage undergraduate volunteers to invite their friends to volunteer.

o Hold a brief orientation for interested undergraduate volunteers. Explain different ways to serve and allow undergraduates to choose how they would like to participate.

o Send e-mails to volunteers to let them know about upcoming microteaching dates, invite them to participate in any upcoming international events, and thank them for their service.

\section{Conversation Partners}

- Post volunteers' contact information on a course management website so that ITAs have easy access to the information.

o Let volunteers know that they need not meet with every ITA who contacts them, but they should respond to every request.

- Encourage ITAs to start their conversation log early in the semester as everyone tends to get busy toward the end of the semester. Also, they should check with ITAs regularly about their progress in completing the log.

$\checkmark$ Have a conversation log template that asks ITAs to record information about conversations including topics discussed, any new words or phrases encountered, what went well during the conversation, challenges, any feedback given, and linguistic areas they would like to improve.

o Collect conversation logs at the end of the semester and provide written feedback.

\section{Classnoom Consultants}

- At an orientation, have potential volunteers practice giving feedback after viewing a sample recorded microteaching demonstration. 
- Throughout the semester, ask classroom consultants to give general feedback to the class as a whole about where they see progress and where they see opportunities for improvement.

$\checkmark$ Ask volunteers to give constructive, actionable feedback that highlights both successful strategies and aspects to work on.

\section{Guest Instructors}

- Meet with undergraduate volunteers at the beginning of the semester to brainstorm potential topics. Encourage volunteers to look at the topics covered in the syllabus and pick one of those topics or propose a new topic.

- Encourage volunteers to use the knowledge gained as a conversation partner and classroom consultant to inform their lesson.

- Before the guest lecture, review a lesson plan with the undergraduate volunteers.

\section{Conclusion}

Both international graduate students and undergraduate volunteers benefit from involvement with PITAP. While international graduate students learn about American undergraduate culture, undergraduates learn about different parts of the world in an informal, relaxed atmosphere. The relationships developed between ITAs and undergraduate volunteers help to reduce anxiety for each when they encounter other ITAs or undergraduates in a classroom setting. The contact with undergraduate volunteers helps to prepare PITAP students to be effective TAs, thereby benefiting all undergraduate students and the university as a whole.

PITAP allows both graduate and undergraduate students to practice their teaching and presenting skills while learning from one another. Through their interactions, ITAs and undergraduate volunteers recognize their differences and similarities. For both groups, being able to communicate effectively, teach, and learn from someone from another part of the world and a different culture will likely prove to be a very important skill.

\section{REFERENCES}

Alberts, H. C. (2008). The challenges and opportunities of foreign borninstructors in the classroom. Journal of Geography in Higher Education, 32(2), 189-203. 
Anderson-Hsieh, J. (1990). Teaching suprasegmentals to international teaching assistants using field-specific materials. English for Specific Purposes, 9(3), 195-214.

Ard, J. (1989). Grounding an ITA curriculum: Theoretical and practical concerns. English for Specific Purposes, 8, 125-138.

Bailey, K. (1983). Foreign teaching assistants at U.S. universities: Problems in interaction and communication. TESOL Quarterly, 17(2), 308-310.

Brown, K. A., Fishman, P. F., \& Jones, N. L. (1990). Legal and policy issues in the language proficiency assessment of international teaching assistants. IHELG Monograph, 90(1).

Byrd, P., \& Constantinides, J. C. (1992). The language of teaching mathematics: Implications for training ITAs. TESOL Quarterly, 26(1), 163-167.

Chiang, S. Y., \& Mi, H. F. (2008). Reformulation as a strategy for managing "understanding uncertainty" in office hour interactions between international teaching assistants and American college students. Intercultural Education, 19(3), 269-281.

Civikly, J. M., \& Muchisky, D. M. (1991). A collaborative approach to ITA training: The TTAs, faculty, TAs, undergraduate interns, and undergraduate students. In J. Nyquist, R. Abbott, D. Wulff, \& J. Sprague (Eds.), Preparing the professoriate of tomorrow to teach (pp. 356-360). Dubuque, IA: Kendall-Hunt.

Constantinides, J. C. (1989). ITA training programs. In J. D. Nyquist \& R. D. Abbott (Eds.), New directions for teaching and leaming: No. 39. Teaching assistants in the 1990s (pp. 71-77). San Francisco, CA: Jossey-Bass.

Damarin, S., \& West, G. (1979). Preparation of foreign graduate students to teach mathematics: An experimental course. American Mathematical Monthly, 86(6), 494-497.

Fisher, M. (1985). Rethinking the "foreign TA problem." In J.D.W. Andrews (Ed.), New directions for teaching and learning: No. 22. Strengthening the teaching assistant faculty (pp. 63-73).

Fitch, F. F., \& Morgan, S. E. (2003). "Not a lick of English": Constructing the ITA identity through student narratives. Communication Education, S2(3), 297-310.

Hahn, L. D. (2004). Primary stress and intelligibility: Research to motivate the teaching of suprasegmentals. TESOL Quarterly, 38(2), 201-223.

Halleck, G. B., \& Moder, C. L. (1995). Testing language and teaching skills of international teaching assistants: The limits of compensatory strategies. TESOL Quarterly, 29(4), 733-758.

Hoekje, B., \& Linnell, K. (1994). "Authenticity" in language testing: Evaluating spoken language tests for international teaching assistants. TESOL Quarterly, 28(1), 103-126. 
Jenkins, S., \& Parra, I. (2003). Multiple layers of meaning in an oral proficiency test: The complementary roles of nonverbal, paralinguistic, and verbal behaviors in assessment decisions. Modern Language Joumal, 87(1), 90-107.

Kaplan, R. B. (1989). The life and times of ITA programs. English for Specific Purposes, 8(2), 109-124.

Kaufman, D., \& Brownworth, B. (Eds.). (2006). Professional development of international teaching assistants. Alexandria, VA: TESOL.

Kim, S., \& Kubota, R. (2012). Supporting nonnative English-speaking instructors to maximize student learning in their courses: A message from the guest editors. Journal on Excellence in College Teaching, 23(3), 1-6.

King, K. (1998). Mandating English proficiency for college instructors: States' responses to the "TA problem." Vanderbilt Journal of Transnational Law, 31, 203-256.

LeGros, N., \& Faez F. (2012). The intersection between intercultural competence and teaching behaviors: A case of international teaching assistants. Journal on Excellence in College Teaching, 23(3), 7-31.

Molholt, G. (1988). Computer-assisted instruction in pronunciation for Chinese speakers of American English. TESOL Quarterly, 22(1), 91-111.

Morley, J. (1991). The pronunciation component in teaching English to speakers of other languages. TESOL Quarterly, 25(3), 481-520.

National Center for Educational Statistics. (2012a). Doctor's degrees conferred by degree-granting institutions, by racelethnicity and field of study: 200910 and 2010-11 [Table]. Retrieved from http://nces.ed.gov/programs/digest /d12/tables/dt12_307.asp

National Center for Educational Statistics. (2012b). Doctor's degrees conferred by degree-granting institutions, by racelethnicity and sex of student: Selected years, 1976-77 through 2010-11 [Table]. Retrieved from http:/nces.ed .gov/programs/digest/d12/tables/dt12_306.asp

National Center for Educational Statistics. (2012c). Foreign students enrolled in institutions of higher education in the United States, by continent, region, and selected countries of origin: Selected years, 1980-81 through 2010-11 [Table]. Retrieved from http://nces.ed.gov/programs/digest/d12/tables /dt12_236.asp

Pickering, L. (2001). The role of tone choice in improving ITA communication in the classroom. TESOL Quarterly, 35(2), 233-255.

Pickering, L. (2004). The structure and function of intonational paragraphs in native and nonnative speaker instructional discourse. English for Specific Purposes, 23, 19-43.

Plakans, B. S. (1997). Undergraduates' experiences with and attitudes toward international teaching assistants. TESOL Quarterly, 31(1), 95-119. 
Rounds, P. L. (1987). Characterizing successful classroom discourse for NNS teaching assistant training. TESOL Quarterly, 21(4), 643-671.

Rubin, D. L. (1992). Nonlanguage factors affecting undergraduates' judgments of nonnative English-speaking teaching assistants. Research in Higher Education, 33(4), 511-531.

Rubin, D. L., \& Smith, K. A. (1990). Effects of accent, ethnicity, and lecture topic on undergraduates' perceptions of nonnative English-speaking teaching assistants. International Journal of Intercultural Relations, 14, 337-353.

Sarkisian, E. (1986). Learning to teach in an American classroom: Narrowing the culture and communication gap for foreign teaching assistants. In M. Svinicki, J. Kurfiss, \& J. Stone (Eds.), To improve the academy: Resources for faculty, instructional, and organizational development, Vol. 5 (pp. 120-131). Stillwater, OK: POD and New Forums Press.

Sarkisian, E. (2006). Teaching American students: A guide for international faculty and teaching assistants in colleges and universities (3rd ed.). Cambridge, MA: Harvard University Press.

Schneider, K., \& Stevens, S. G. (1991). American undergraduate students as trainers in an international teaching assistant training program. In J. Nyquist, R. Abbott, D. Wulff, \& J. Sprague (Eds.), Preparing the professoriate of tomorrow to teach (pp. 361-367). Dubuque, LA: Kendall-Hunt.

Smith, R. M., \& Ainsworth, C. L. (1987). It's working: A training program for foreign tcaching assistants. In J. Kurfiss, L. Hilsen, L. Mortensen, \& E. Wadsworth (Eds.), To improve the academy: Resources for faculty, instructional, and organizational development, Vol. 6 (pp. 157-167). Stillwater, OK: POD and New Forums Press.

Tyler, A. (1992). Discourse structure and the perception of incoherence in international teaching assistants' spoken discourse. TESOL Quarterly, 26(4), 713-729.

Williams, G. M. (2011). Examining classroom negotiation strategies of international teaching assistants. International Journal for the Scholarship of Teaching and Learning, S(1), 1-16.

Williams, J. (1992). Planning, discourse marking, and the comprehensibility of international teaching assistants. TESOL Quarterly, 26(4), 693.

$\mathrm{Xi}, \mathrm{X}$. (2007). Validating TOEFL iBT speaking and setting score requirements for ITA screening. Language Assessment Quarterly, 4(4), 318-351.

Yule, G., \& Hoffman, P. (1990). Predicting success for international teaching assistants in a U.S. university. TESOL Quarterly, 24(2), 227-243. 